\title{
Scholarly Communication in the Age of New Media
}

\author{
Brian Foster, Provost, University of Missouri
}

$\mathbf{T}$ The Broad Perspective

It is important to put scholarly communication in context by addressing the very broad idea of why scholarly communication is important. One of the main missions of universities is to create new knowledge and innovations-i.e., research. This new knowledge needs to be disseminated - to be exchanged such that the scholars creating the new knowledge are in touch with others, all contributing to the original ideas and new insights of each other. But scholarly communication is not just about people working at the same time on problems that are somehow connected; it is also about archiving research results for investigators of the future. In addition, it is critical that higher education is very much about educating students to be creative and innovative and, in this sense, access to research results and processes is critical for effective education. In short, scholarly communication is critical for both the research and educational missions of universities.

Given the centrality of scholarly communication to the mission of higher education, it is unsettling that all we know about the current model is that it will not work in the future. There are many reasons that this is true, many related to new media technologies that have dramatically disrupted the business models for both print and digital scholarly publishing-i.e., scholarly journals, university presses, and other organizations that publish research results. This is not a new idea: it was spelled out as far back as 1980 in the White House Conference on Libraries and Information Services (Lamm, 1996, p. 127). Journals are pretty much going digital. Books are moving rapidly in that direction, and the future of university presses as we know them is highly problematic (Withey, et al., 2011). It is im- portant to emphasize that scholarly publishing is just one part of scholarly communication-which is part of the problem, as will be discussed in detail below. Journals and books fit into a broad scholarly communication environment in rather different ways-into the broad mix of "media forms" that include both formal and informal transfer of information. For example:

Informal communication among scholars is in some ways the most important kind of scholarly communication. People working on similar problems often discuss their work informally at meetings, over a meal, having a beer-completely unstructured conversations that are timely as the work is being done. In addition, people working on different kinds of problems may discover entirely unexpected connections 
between their areas, opening exciting new directions for their research.

Oral presentation of research results occurs in many different kinds of venues, generally when the work is far enough advanced that at least preliminary results can be reported. Such presentations occur in formal meetings of, say, scholarly organizations, in symposia, or as guest speakers in many other kinds of venues. This tends to be relatively early in the history of a project.

Often there is pre-publication distribution of manuscripts to colleagues working in similar/connected areas.

Proceedings from scholarly meetings are often the earliest and most critical versions of articles in journalsgenerally significantly earlier than publication in classic, high-ranking scholarly journals. Such proceedings may often also be a significant archiving functionespecially for "papers" that are not subsequently published in "journals" preserving the work and making it available to future generations of scholars.

Articles in scholarly journals are the gold-medal scholarly communication media in many academic disciplines. This kind of publishing is critical for faculty to be promoted and otherwise recognized, and it is a critical archiving function that makes scholarly results available for generations of scholars in the future. It comes late in the research project, however-generally after the scholarship is complete, and is often of little immediate relevance to active research.

Edited books of articles and chapters provide another medium for disseminating scholarly outcomes; as with journals, the importance of such publications varies by scholarly discipline.

Monographs provide the most critical medium for scholarly publication in many disciplines-especially in the humanities and certain social science areas. Many such works are published by university presses-scholarly publishing enterprises run by universities that publish scholarly works whose audience will be primarily scholars.

Much significant work is done by doctoral students, whose research is documented in their dissertations. Much of this work is later disseminated in other forms-presentations at meetings, articles, monographs-but some is never published and archived in these kinds of venues, and in such cases the dissertations are the major archiving resource for the research results.

Most of the focus of this paper is on traditional late-stage scholarly communication-i.e., on publication. The main point is that we are really looking beyond books and journals as we know them to media of the future that are not known. The concept of the "book" or "journal" may be last century-largely a function of changing media, but also a function of changing markets, changing library practice, and other issues. A recent report from the Association of University Presses (Withey, et al., 2011) says: "e-books lend themselves to new forms of distribution...breaking down the concept of the "book" in favor of packaging content..." Similar thoughts apply to journals, which as noted above have moved far toward digital format and distribution technologies. Even more transformative, however, is the question of why a digital "journal" 
could not publish modular "books" in the form of "article-like chapters". Such modules could include much more than text-e.g., audio, interactive elements, graphic content, and manipulative elements (e.g., simulations). Are books and journals as we know them the buggy whips of the twenty-first century?

Principles of Scholarly Communication

One of the most important issues for us to address as we navigate the future of scholarly communication is the deep and compelling culture of higher education that frames the principles of scholarly communication. These are issues for which faculty and others in the scholarly world have deep ethical values. That is, we must be clear about the desired benefits and effects of scholarly publishing in this broad scholarly context.

Perhaps the most compelling principle behind faculty members' ideas about scholarly publishing is that there should be open communication with regard to content (but also see Harley, et al., 2010, p. 13, on disciplinary differences in openness). Scholarly results MUST be freely accessible to the scholarly world-and to those who may use such results for applications in business, government, or other domains. We will come back to this matter in several ways. One that is of increasing concern at the present time is that there are now many limitations on open communication that arise from security and commercialization interests. There seem to be three main areas of concern.

Issues of protecting intellectual property (IP) have become increasingly important and restrictive in the past few years, especially as universities' com- mitment to economic development has increased, as has commercialization of IP created by the universities' researchers. The issue is closely related to the issues underlying the Bayh-Dole act of 1980, which recognized that if IP cannot be protected, much will never come to public good, since the development costs cannot be justified without such protection. Thus, as IP development and commercialization has become a central part of universities' mission, the implications for free and open communication about research results have been negative. There is no clear and simple answer to this conflict, but it is one that must be recognized.

As national security issues became ever more compelling-especially following 9/11 - the transfer (intentional or otherwise) of certain IP with security implications became very sensitive. Export control policies that limit the risk of security-sensitive IP leaks have now become a significant limit on open communication of research results. But export control now goes far beyond the open communication of research results - for example, to limiting the presence of international students in a lab with instrumentation with potential security relevance. Moreover, students who work in labs and/or with professors whose work has export control sensitivity may find that their theses or dissertations are embargoed. Since export control began, the grounds for limiting communication about and/or participation in research has expanded to include the transfer of information about IP that has significant economic implications: e.g., transferring information about an economically transformational technolo- 
gy to another country through scholarly publishing, international collaboration of scholars, or having international GAs in a lab.

Classified research has long been a hard limit on scholarly communication and continues to be a significant issue.

Another critical element of scholarly communication is the validation of the quality of the work (Harley, et al., 2010, p. 10,12). There are actually many concerns about the increasing number of low-quality publications, some from self-publishing, vanity "academic presses", and reduced quality of peer review. In any case, the main quality assurance mechanism for scholarly publishing is peer review, the vetting process by which articles, books, presentations at meetings of scholarly organizations, proceedings, and other modes of scholarly communication is done. Basically, the idea is that highly qualified peers of the researcher whose work is being validated read the work and express their judgment on the validity and impact of the work. Some of this kind of peer review occurs very early in the scholarly process-e.g., for grant proposals-but much comes very late in the process after the research is completed and being considered for publication-one might say at the "archival stage." This is a very important issue-that work archived in prominent (i.e., respected) "publications" has been vetted and can be considered "reliable."

There are some significant issues about such peer review. One is the question of whether it is entirely consistent with the principle of open scholarly communication. We know that the most respected publishing venues tend to be conservative, raising the question of whether really innovative and highimpact research will be "accepted" for publication. That is to say, the mindset of peer review is restrictive. This stems from the idea that for journals and presses, the lower the acceptance rate, the higher the perceived quality is seen to be. Peer review thus becomes a central element of assessment for academic ratings of individuals' work, and it is thus critical for promotion and tenure, hiring, awards, NAS membership, and other quality assessment circumstances. It also becomes a core element for ratings of academic programs and of universities. Like so many other elements of scholarly publication, peer review becomes a tradeoff: open access, real innovation, and validation of quality. And, again, there are no clear and simple answers (Harley, et al, 2010, p. 22; Harley, et al., 2011).

In any case, peer review in its current form is a costly element of publishing, both for journals and books. It is not that the peer reviewers get paid to do their reviews; rather, what is costly is the vetting of the potential reviewers and handling the clerical and evaluative function after the reviews are received. And, more important, it is not just the works that are published that are peer reviewed, but for the most highly regarded venues, the number of reviews greatly exceeds the number of publications - the restrictive criterion for stature being a driver of such dynamics. There have been some discussions of alternative methods of peer review-e.g., postpublication peer review-but there is at present no consensus on good practice for the future. 
There has also been a great deal of discussion of various models of open access and the role of peer review (Withey, et al., 2011, p. 14-15). One model of open access keeps the traditional model of peer review in place. "Open access" is not the "acquisition" or "acceptance" model, but the model for access to the ultimately peer-reviewed work that appears. What is "open" is access to the "publication." But some models extend the "open" matter to acceptance, thus addressing the question of whether peer review, which is inherently conservative, violates "openness" of communication; but this practice is not so clearly in line with the idea that the "published" research should be validated before being open to all potential readers.

Another issue that significantly impacts issues of prestige, rankings, and access by scholars to scholarly publications is interdisciplinary scholarship (Harley, et al., 2010, pp. 7-8, 15-17). Much of the highest impact research today is interdisciplinary. But, that said, most of the high-prestige publishing is extremely discipline centric, and thus conservative, in the sense that the works that are "accepted" are at the center of the disciplines. Although the interdisciplinary work tends to be more high impact, the prestige of journals or presses accepting such work tends to be lower than those that are highly restrictive and disciplinary centric. Therefore, the journals with a high "impact factor" tend to be those that are disciplinary centric. This is a daunting issue for scholars doing high-impact interdisciplinary work, since it very negatively impacts their prospects for promotion and tenure, for hiring, and for other processes that involve evaluation of scholarly work. Accordingly, it poses significant disincentives for taking on risky, interdisciplinary, and potentially high-impact research. And accordingly, interdisciplinary work tends to impact rankings of departments, programs, and institutions in complicated ways (e.g., if many faculty are doing high-impact interdisciplinary work not published in high impact journals).

In many ways, the most important function of scholarly publication is the archival function. As we have indicated, most of the scholarly communication occurs before publication of the results. Leading researchers in a given area are generally in close, constant contact with peers. They exchange information at conferences, symposia, and in contexts as informal as having a beer together. But journals and monographs archive the research results for the long future. The use by future scholars may be WAY in the future. In fact, few pieces get much attention in the future, but some do... and may be critical for very high impact scholarly success in the distant future. But this kind of archiving function raises some significant questions about the long-term viability of the digital publications as an archival function. For example, there does not seem to be a viable plan to migrate the staggering amounts of "archived" digital data if significant new technologies emerge. Can we really migrate a trillion petabytes of data when the current technologies are replaced?

Finally, with respect to the principles of scholarly communication, it is critical that the educational function be 
considered. Articles and monographs are critical resources, especially for advanced (e.g., graduate, professional) education. Advanced undergraduate and graduate students' resources are to a large degree reading the results of earlier scholarly research. But there are many practical and legal challenges to the use of such materials in digital format. For instance, imagine a multi-campus graduate program in which courses from several campuses serve students of other campuses. If the licensing of journals restricts access to members of the homecampus community, students at the other campuses will be unable to access significant educational materials. We at MU have experienced this problem. So, there is a tradeoff for whether the library pays significantly higher licensing fees for a journal to provide broader access or whether it subscribes to more journals for the campus community.

Also in the educational area, there are many questions about how new modes of "publication" fit in the picture with regard to IP and other issues. It is a certainty, at least in my view, that we will see dramatic changes in the formats of educational materials. These issues will create daunting questions with respect to IP rights of faculty creating the materials. But even more importantly, it will create major problems about cost of very high-impact materials created by innovative publishers (e.g., simulations by Disney or Microsoft developed at the cost of tens of millions of dollars, useful for hands-on learning in small learning groups). We have to ask if textbooks as we know them will exist in the future. Why would we not move to flexible modular digital "chapters" that can be aggregated like "articles" or "book chapters" and linked to very high-level technologies that facilitate hands on learning-e.g., a simulation of forest ecosystems, or of businesses, or of urban development?

\section{Practical questions}

There are many practical/operational questions about the future of scholarly communicationespecially scholarly publishing. There is a lot of discussion of the fiscal "solution" being digital publishing. The fact is that the cost of digital publication is only about $25 \%$ less than the cost of paper publication, assuming that the same level of peer review and other functions are similar. The bottom line: the cost of digital publication is nearly as expensive as paper publication. Savings is not the issue for digital publication. The model for revenue generation for digital journals is clearer than for other publishing media such as monographs, but it's not clear that it is sustainable in any case. An important question is whether digital "journals" may be repositioned in scholarly publishing in areas where monographs have been dominant? Could a "journal" do "monographs"? What would be the effects on monographbased disciplines... and on university presses?

There are other challenges to the fiscal viability of university presses. For instance, the sales volume for the typical monograph over about 10 years fell from about 1,500 to 600-700 copies (e.g., Lamm, 1996, p. 136)). Another limitation on revenues for University Presses and a challenge to the archival function is the "library purchase on demand" model, in which libraries purchase books only af- 
ter there is a demand (i.e., a client request for access) for the book. This kind of purchasing is becoming very common in library practice, and it has potential to significantly impact the business model of university presses.

Whatever the future path, there will be unexpected consequences. There are very complicated implications for the academic principles of scholarly communication-e.g., peer review is called into question, and the potential implications for promotion and tenure and hiring processes can be severely impacted (Harley, et al., 2011). The issues of "impact factors" and related matters were discussed above. But even more important, many other matters affect the appearance of impact, prestige, and stature of publications and, therefore, feedback on program stature and institutional rankings. A more concrete issue: there is a perspective by which digital subscriptions in libraries limit access to scholarly results. One doesn't need to "sign in" to take a paper volume off the shelf in the Library; but if one wants access to the digital journals, one has to be a "member" of the "organization" (e.g., university) to be able to "sign in" to get access to the on-line material-a condition of the licensing. Of course, licensing could be done in a much more expensive and inclusive mode...but what is the tradeoff with the number of subscriptions the library can sustain?

\section{University of Missouri Press}

A compelling example of the urgency and the complexity of the scholarly publishing issues has been captured by the national-even internationalpush-back that occurred when the University of Missouri System President an- nounced that the University of Missouri Press would be closed to save the $\$ 400,000$ per year subsidy (and additional deficits after the subsidy) that were being paid. It was not just the University of Missouri faculty's outrage-even more, it was a national response (outrage is perhaps too strong, but maybe not) that the University would abandon its obligation as a major research university to support one of its most important functions: scholarship (see a small sample of the press coverage: Singer 2012, Williams 2012, and Eligon 2012). The President's decision was driven by the daunting fiscal challenges facing the University of Missouri as state appropriations dropped and costs continued to rise. What he perhaps did not realize was the degree to which scholarly communication is central to the research mission of higher education. It is not surprising that research journals and university presses are not selfsustaining, but their function, as outlined above, is critical to the scholarly mission.

Fortunately, there had been very productive discussions for several months prior to the President's announcement, involving both System and MU Campus people-faculty, administrators, staff, and others-about the daunting challenges facing university presses. And when President Wolfe's announcement occurred, there was a rich set of discussions on which the MU campus could build a new vision for the University of Missouri Press moving to the Campus. Basically, the ideas were based on two main premises. First, the Press must continue its main function of disseminating and archiving major 
scholarly outcomes. From the point of view of authors, it would not look different than the previous press model in the short term (e.g., would continue print publications, strong peer review in the traditional sense, and would do marketing at least as effectively as in the past). More importantly, it would be embedded in the campus academic environment in a way that was not possible when it was a "System" function. Namely, it would have both an instructional and research connection that would position it well in the rapidly changing environment for scholarly communication.

The details of this academic engagement have not yet been worked out, but the broad vision is clear. On the one hand, our international academic program strengths in Journalism, Library Science, Creative Writing, and other areas would develop an academic program (perhaps a certificate program) that would prepare students for careers in the volatile world of scholarly communication. One element of such a program would be internships and student employment at the Press, with students mentored by editorial and other staff who have a faculty function. On the other hand, we could build on our strengths in new media (our world-class Journalism program and the Reynolds Journalism Institute), Library Science, Creative Writing, and the University Libraries to do cutting-edge research on how scholarly communication is changing. From this latter point of view, MU has potential to become a world leader in not just understanding where scholarly communication is going, but in shaping a major university press that could become a model for others as these complex dynamics play out.

From this perspective, the Press becomes an important entity much like an internationally prominent research lab or center. It is embedded in the broad academic mission of the University, providing a venue for strong graduate student learning experiences at the same time as it is linked to a major research program. There are many models for such engagement at the University: science research labs, clinical programs, the Law Review, Medical Education, and others. We believe this is a strong, forward-looking model for scholarly publishing that may become a model for the future.

\section{Bottom Line}

The issues involving scholarly communication are very complex. There is no clear, simple answer. A key issue is that we must identify the unintended consequences of change-and the only certainty is that dramatic change will occur. We know that media technologies are impacting scholarly publication in profound ways. Costs of digital communication will be high-not much less than paper. A sustainable revenue stream must be found. In any case, we must mitigate the unintended consequences such as limiting access as a condition of library subscriptions. Open access, peer review, and "impact factors" are hard to reconcile. Our values about "free and open communication" and "peer review" and "high impact/prestigious" research are contradictory with one another. Monographs, journals, and other media forms will change in the digital environment. We are likely to see entirely new forms that 
do not align with journals and monographs - the "buggy whips" of scholarly communication.

There are no clear answers. We need to have deep and open dialogue. We need some models for new models for scholarly communication-perhaps the new model for the University of Missouri Press. And we need to understand that the only thing we really know is that the current system is not sustainable.

\section{Acknowledgements}

I would like to thank participants in the Merrill Retreat for their useful feedback on a very early, oral version of this paper. I would also like to thank Don Lamm (former CEO of Norton Publishing and former member of several University Press boards) and Lynne Withey (former director of the University of California Press) for their extraordinarily helpful comments on a near-final draft of this paper. They bring very different and very complementary perspectives to the issues of scholarly communication and changing media technologies.

\section{$\underline{\text { References }}$}

1. Eligon, John. "Plan to Close University of Missouri Press Stirs Anger." New York Times, July 18, 2012.

2. Harley, Diane, and Sophia Krzys Acord. Peer Review in Academic Promotion and Publishing: Its Meaning, Locus, and Future. 2011. Berkeley, CA: Center for Studies in Higher Education.

3. Harley, Diane, Sophia Krzys Acord, and Sarah Earl-Novell. Assessing the Future Landscape of Scholarly Communication. 2010. Berkeley, CA: Center for Studies in Higher Education.

4. Lamm, Donald. "Libraries and Publishers: A Partnership at Risk." Daedalus, Fall, 1996.

5. Singer, Dale. "New Version of UM Press will Involve Students, Research." St. Louis Beacon, July 16, 2012.

6. Williams, Mara Rose. "After Outcry, University of Missouri Presents New Plan for Press." Kansas City Star, July 17, 2012.

7. Withey, Lynne, Steve Cohn, Ellen Faran, Michael Jensen, Garrett Kiely, Will Underwood, and Bruce Wilcox. Sustaining Scholarly Publishing: New Business Models for University Presses. 2011. New York, NY., The Association of American University Presses. 